\title{
DIFFERENTIAL POLLEN-TUBE GROWTH RATES AND NONRANDOM FERTILIZATION IN HIBISCUS MOSCHEUTOS (MALVACEAE) ${ }^{1}$
}

\author{
Allison A. SnOw ${ }^{2}$ And Timothy P. Spira \\ Department of Plant Biology, Ohio State University, Columbus, Ohio 43210, and \\ the University of Michigan Biological Station, Pellston, Michigan 49769; and \\ Biology Department, Georgia Southern University, Statesboro, Georgia 30460, and \\ the Smithsonian Environmental Research Center, Box 28, Edgewater, Maryland 21037
}

\begin{abstract}
The prevalence of nonrandom fertilization due to postpollination events has rarely been studied in natural populations, despite important implications for outcrossing rates, mate choice, and plant fitness. Nonrandom paternity within fruits can be caused by both unequal fertilization and unequal embryo abortion. Using self-compatible Hibiscus moscheutos, we studied the potential for nonrandom fertilization by comparing growth rates of pollen-tubes from different donors. The branched style of Hibiscus allowed within-flower comparisons between pollen donors. Relative pollen-tube growth rates were determined by applying pollen from pairs of donors to different stigmas on adjacent stylar branches. We then measured the number of callose plugs per tube in cross-sectional transects across the style after $3 \mathrm{hr}$. We demonstrate that rates of callose plug formation can be used as a sensitive indicator of relative pollen-tube growth rate. Differences between pollen donors were common and repeatable. Self-pollen-tubes grew slower than outcross pollen-tubes in some crosses and faster in others. Allozyme variation in glucose phosphate isomerase was used to show that individuals with fast-growing pollen-tubes sired a disproportionate number of seeds following mixed pollinations (up to $72 \%$ ). Since seed abortion was negligible, we conclude that variation in pollen-tube growth rates leads to nonrandom paternity within fruits.
\end{abstract}

The outcome of pollen-tube competition can have major genetic consequences for plant populations. In self-compatible species, for example, outcross pollen-tubes may reach the ovules more quickly than self-tubes, thereby contributing to reduced selfing rates (Bateman, 1956; Barnes and Cleveland, 1963; Weller and Ornduff, 1977, 1989; Casper, Sayigh, and Lee, 1988; Aizen, Searcy, and Mulcahy, 1990). Nonrandom fertilization can also occur following simultaneous deposition of pollen from different outcross donors (Marshall and Ellstrand, 1986; Snow and Mazer, 1988).

Random fertilization is the null model in population genetics, but little is known about

\footnotetext{
${ }^{1}$ Received for publication 28 November 1990; revision accepted 3 June 1991.

The authors thank R. Bertin, M. Cruzan, C. Galen, R. Nakamura, and D. Schoen for reviewing the manuscript; D. Crawford, J. Hamrick, and M. Loveless for advice on electrophoresis; D. Whigham for logistical support; and P. Bradley, S. Whisler, R. Klips, and J. O'Neill for technical assistance. This research was supported by NSF grants BSR 8906667 and 8906959 , the Smithsonian Environmental Research Center, a University Seed Grant from O.S.U. to AAS, and a Faculty Research Committee Grant from G.S.U. to TPS.

${ }^{2}$ Author for correspondence, current address: Department of Plant Biology, Ohio State University, Columbus, OH 43210-1293.
}

the validity of this model for natural populations (Clegg and Epperson, 1985). In addition to possible effects on population genetic structure, pollen-tube competition could influence the number of seeds a plant sires (Jones, 1922; Marshall and Ellstrand, 1986; Bertin, 1990), levels of inbreeding depression (Schemske, 1983; Schoen, 1983), and the fitness of seeds sired by different outcross donors (Bertin, 1982; Marshall and Ellstrand, 1986; Waser et al., 1987; but see Mazer, 1987). One way that progeny fitness may vary is through selection among microgametophytes: in several cultivated species, pollen-tube growth rates are positively correlated with sporophytic growth rates (reviewed in Mulcahy and Bergamini Mulcahy, 1987; but see Snow, 1990).

Despite the potential significance of variation in pollen-tube growth rates, few investigators have quantified differences among pollen donors, and fewer still have done so by controlling for variation among flowers (but see Aizen, Searcy, and Mulcahy, 1990; Cruzan, 1990). One problem is that the most widely used technique for viewing pollen-tubesMartin's (1959) fluorescence method-is often impractical for comparing their growth rates because young tubes do not produce enough callose to fluoresce when stained. Even mature tubes can be difficult to see, although the callose 
plugs within them fluoresce brightly (e.g., Weller and Ornduff, 1989; A. Snow, personal observation). In many species, growing pollentubes produce callose plugs at very regular intervals behind the cytoplasm, which remains near the tip of the tube (Cresti and van Went, 1976; Dumas and Knox, 1983; A. Snow, personal observation).

Here we show that the rate of callose plug formation can be used as a measure of relative pollen-tube growth rate, and that growth rates differ among pollen donors. We also use electrophoretic markers to demonstrate that when pollen-tubes from different individuals compete for ovules, differences in pollen-tube growth rate are correlated with differences in the proportion of seeds sired. Finally, we conclude that seed abortion is negligible following self- and outcross pollinations.

\section{MATERIALS AND METHODS}

The study species-Hibiscus moscheutos L. (Malvaceae) is a self-compatible, herbaceous perennial found in brackish and freshwater marshes of the eastern United States (Brown and Brown, 1984; Spira, 1989). Our study population is located at the Mill Swamp Study Area of the Smithsonian Environmental Research Center in Edgewater, Maryland. The major reason for choosing this species is that natural rates of pollen deposition are very high, leading to strong competition among pollen-tubes for ovules (Spira, 1989; Spira et al., unpublished data). On the morning of anthesis, bees often delivered six times more pollen than is needed for maximum seed set (about 100 seeds per fruit; Spira et al., unpublished data).

The 6-cm-long style and large pollen grains (150 $\mu \mathrm{m}$ diam) make this species attractive for pollen-tube growth studies. The pistil has five stylar branches (1-cm long), so different pollination treatments can be applied to separate stigmas of the same flower. This alleviates the problem of among-flower variation in pollentube growth rates (Aizen, Searcy, and Mulcahy, 1990).

Flowers open for a single day and are pollinated primarily by a specialist anthophorid bee, Ptilothrix bombiformis, and also by bumblebees, Bombus pennsylvanicus (Rust, 1980; Spira, 1989). Spatial separation of anthers and stigmas prevents autopollination, but bees can transfer pollen within and among flowers on the same plant (Spira, 1989). It is likely that bees deposit mixtures of pollen from several individuals, including some self-pollen. Seed set following self- and outcross pollination does not differ significantly (Spira, 1989; this study).
Timing of tube growth and callose plug formation-Field experiment-To characterize pollen-tube growth rates in the field, we pollinated newly opened flowers that had been bagged in the bud with netting. Stigmas and styles were collected 3,6 , or $9 \mathrm{hr}$ after pollination. For each interval, we applied pollen from flowers of the same donor to five flowers on each of five recipient plants (individual genets were easily distinguished). Pollinations were performed on two consecutive sunny days in August 1987. Stigmas were excised and saved at the time of collection so that the number of pollen grains could be counted under a dissecting microscope (pollen grains of $H$. moscheutos fall off the stigma in solution). Pistils were fixed in $70 \%$ ethyl alcohol and refrigerated immediately to halt further pollen-tube growth.

At a later date, styles were cleared for fluorescence microscopy (Martin, 1959), and the proportion of grains with pollen-tubes at the base of the style was determined. The best fluorescence was achieved by clearing the styles in $8 \mathrm{~N} \mathrm{NaOH}$ for $90 \mathrm{~min}$ at $60 \mathrm{C}$. The styles were then rinsed in tap water and stored in 1 $\mathrm{M} \mathrm{K}_{3} \mathrm{PO}_{4}$ with $0.0015 \%$ analine blue. After at least $2 \mathrm{hr}$ in stain, the styles were placed on a microscope slide with a drop of gylcerol, squashed, and viewed through a compound epifluorescence microscope with appropriate filters.

Laboratory experiment-A second experiment was designed to determine whether callose plug formation could be used as an index of relative pollen-tube growth rate in a given style. Pollen-tubes were allowed to grow during two time intervals, 3 and $5 \mathrm{hr}$, in adjacent stylar branches on 30 picked flowers (bagged as buds). Each recipient flower came from a different individual, and its pedicel was placed in water immediately after cutting. We pollinated one stigma at $0900 \mathrm{hr}$ and the other $2 \mathrm{hr}$ later, using pollen from a single unrelated donor. The two stylar branches were labeled with permanent ink for later identification under the microscope. Flowers were then incubated in the laboratory at $30 \mathrm{C}$. Three hours after the second pollination, we excised the stigmas for pollen counts and prepared the styles as described above.

The numbers of tubes and plugs were counted in a standardized cross-sectional area of the style, where pollen-tubes from the two treatments converged (about $2-3 \mathrm{~cm}$ below the stig$\mathrm{ma})$. The longitudinal width of this area (692 $\mu \mathrm{m})$ was approximately equal to the average distance between the plugs in any given tube (A. Snow, personal observation). Therefore, 
TABLE 1. Relative pollen-tube growth rates for pairs of pollen donors ${ }^{a}$

\begin{tabular}{|c|c|c|c|}
\hline \multirow[b]{2}{*}{ Recipient } & \multicolumn{3}{|c|}{$\begin{array}{c}\text { Mean number of callose plugs per pollen-tube } \\
\text { Pollen donors }\end{array}$} \\
\hline & Self ${ }^{b}$ vs. A & Selfo vs. B & $A^{\mathrm{b}}$ vs. $B$ \\
\hline 1 & $\begin{array}{l}0.51 \text { vs. } 0.53 \mathrm{NS} \\
\text { (11) }\end{array}$ & $\frac{0.48 \text { vs. } 0.39^{*}}{(14)}$ & $\frac{0.65 \text { vs. } 0.49^{*}}{(15)}$ \\
\hline 2 & $\underline{0.48 \text { vs. } 0.17^{* * *}}$ & $\begin{array}{l}0.35 \text { vs. } 0.37 \mathrm{NS} \\
\text { (9) }\end{array}$ & 0.27 vs. $0.53^{*}$ \\
\hline 3 & $\begin{array}{l}0.17 \text { vs. } 0.41^{* *} \\
\text { (9) }\end{array}$ & 0.34 vs. $0.56 \dagger$ & \\
\hline 4 & $\underline{0.31}_{\text {(7) }}$ vs. $0.16^{*}$ & $\begin{array}{l}0.37 \text { vs. } 0.41 \mathrm{NS} \\
\text { (8) }\end{array}$ & \\
\hline 5 & $\begin{array}{l}0.31 \text { vs. } 0.33 \mathrm{NS} \\
\text { (7) }\end{array}$ & & $\frac{0.47}{\text { vs. } 0.32 \dagger}$ \\
\hline 6 & $\begin{array}{l}0.25 \text { vs. } 0.46^{*} \\
\text { (14) }\end{array}$ & & 0.37 vs. $0.60^{* *}$ \\
\hline 7 & $\begin{array}{l}0.31 \text { vs. } 0.43^{* * *} \\
\text { (11) }\end{array}$ & & \\
\hline 8 & 0.24 vs. $0.63^{* * *}$ & & \\
\hline 9 & $\begin{array}{l}0.42 \text { vs. } 0.50 \mathrm{NS} \\
\text { (14) }\end{array}$ & & \\
\hline 10 & $\begin{array}{l}0.27 \text { vs. } 0.20 \mathrm{NS} \\
\text { (7) }\end{array}$ & & \\
\hline 11 & 0.33 vs. $0.60^{* *}$ & & \\
\hline 12 & 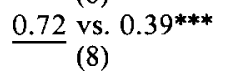 & & \\
\hline
\end{tabular}

${ }^{a}$ Different outcross donors (A and/or B) were used on each recipient plant. Paired $t$-tests were conducted using the number of callose plugs per pollen-tube for each donor in a pair (NS = not significant, $\dagger P<0.10, * P<0.05, * *$ $\left.P<0.01,{ }^{* * *} P<0.001\right)$. Back-transformed means are shown with sample sizes in parentheses. The pollen donor with faster-growing tubes is underlined when differences were significant.

${ }^{b}$ Listed first below.

for each tube with any plugs, only one plug was counted on average within this area.

Paired measurements within flowers were analyzed in paired $t$-tests to determine effects of incubation time ( $3 \mathrm{hr} v \mathrm{ss} .5 \mathrm{hr}$ ) on the number of plugs per pollen-tube. These and subsequent statistical analyses were performed using SAS (SAS Institute, Inc., 1985). All proportions involving pollen germination and tube growth were arcsin-transformed for statistical analysis.

Comparisons of pollen from different donors - We compared growth rates of pollentubes from pairs of donors by applying pollen to different stigmas of the same pistil. The purpose of this experiment was to test for differences between donors and, when possible, to test for consistent rankings among donors when three donors were used on a given recipient (Recipients 1 and 2, Table 1). We also tested for differences between donors in the proportion of pollen grains that germinated after 3 hr.

For each of 12 recipient plants in the field population, we compared self-pollen with pollen from one or two outcross donors, using different outcross donors on each recipient. Each cross was replicated six to 15 times over a period of several days, depending on availability of flowers. Four of the maternal plants had many flowers, so on these we also compared two outcross donors against each other. Pollen donors were at least $10 \mathrm{~m}$ away from their recipient and each other. The amount of pollen deposited ranged from 52 to 153 grains per stigma. Within this range, the number of grains per stigma was not correlated with percent germination $\left(r^{2}=0.01, N=82\right)$, contrary to what some previous studies have shown (e.g., Brewbaker and Majumder, 1961; Schemske and Fenster, 1983).

Picked flowers were pollinated in the laboratory, incubated for $3 \mathrm{hr}$ at $30 \mathrm{C}$, and processed as above. For each donor, we determined the proportion of grains that germinated and the number of callose plugs per tube. As above, callose plugs were counted in cross-sectional transects where tubes from the two donors converged, about $3 \mathrm{~cm}$ below the stigma. The position of each transect varied somewhat among flowers, depending on how far down the style the pollen-tube paths remained distinguishable. By comparing pollen donors in 
TABLE 2. Comparisons between pollen-tube growth rate and the proportion of seeds sired by competing donors ${ }^{\mathrm{a}}$

\begin{tabular}{|c|c|c|c|}
\hline Recipient & Pollen donors & $\begin{array}{l}\text { Difference between } \\
\text { donors in number } \\
\text { of plugs per tube } \\
\text { (number of flowers) }\end{array}$ & $\begin{array}{c}\text { Proportion of seeds } \\
\text { sired by faster } \\
\text { pollen donor } \\
\text { (number of fruits) }\end{array}$ \\
\hline 7 & $\underline{25}$ vs. 10 & $\begin{array}{l}0.30^{* * *} \\
(11)^{2 *}\end{array}$ & $\begin{array}{l}0.68^{*} \\
(5)\end{array}$ \\
\hline $34 a$ & $\underline{23}$ vs. self & $\begin{array}{l}0.28^{* * *} \\
(10)\end{array}$ & $\begin{array}{l}0.66^{*} \\
(9)\end{array}$ \\
\hline 33 & $\underline{25}$ vs. self & $\begin{array}{l}0.24^{* *} \\
(15)\end{array}$ & $\begin{array}{l}0.57^{*} \\
(7)\end{array}$ \\
\hline $36 \mathrm{~b}$ & $\underline{23}$ vs. self & $\begin{array}{l}0.23^{*} \\
(14)\end{array}$ & $\begin{array}{l}0.72^{*} \\
(9)\end{array}$ \\
\hline $34 b$ & $\underline{23}$ vs. self & $\begin{array}{l}0.18^{*} \\
(15)\end{array}$ & $\begin{array}{l}0.62^{*} \\
(9)\end{array}$ \\
\hline 35 & 2 vs. self & $\begin{array}{c}0.14 \\
(12)\end{array}$ & $\begin{array}{l}0.51 \\
(7)\end{array}$ \\
\hline 32 & 13 vs. self & $\begin{array}{l}0.11 \\
(10)\end{array}$ & $\begin{array}{l}0.56 \\
(7)\end{array}$ \\
\hline 1 & 31 vs. 5 & $\begin{array}{l}0.04 \\
(8)\end{array}$ & $\begin{array}{l}0.53 \\
(6)\end{array}$ \\
\hline $36 a$ & 2 vs. self & $\begin{array}{l}0.01 \\
(14)\end{array}$ & $\begin{array}{l}0.54 \\
(10)\end{array}$ \\
\hline 16 & 13 vs. self & $\begin{array}{l}0.01 \\
(14)\end{array}$ & $\begin{array}{l}0.55 \\
(9)\end{array}$ \\
\hline
\end{tabular}

a The pollen donor with faster-growing tubes is underlined when difference was significant (crosses above the line); paired $t$-tests and significance levels as in Table 1. Differences in seed set are based on sample sizes large enough to detect at least a $10 \%$ difference at $P<0.05\left(\chi^{2}\right.$ test; see Materials and Methods). ID numbers consistent with Table 1.

this way, we obtained a relative rather than an absolute measure of pollen-tube growth rate. Data were analyzed using paired $t$-tests, as described above.

Pollen-tube growth rate and nonrandom fertilization-Electrophoretic markers were used to confirm that differences in pollen-tube growth rates are associated with disproportionate seed set following pollen-tube competition. Hibiscus moscheutos plants from the Mill Swamp population have three Mendelian alleles for GPI (glucose phosphate isomerase; unpublished data; starch gel electrophoresis was performed with Gottlieb's [1981] extraction buffer and procedures described in Soltis et al. [1983]). Plants with a variety of GPI genotypes were dug up in the fall of 1988 , stored in a cold room, and cultivated in a greenhouse the following spring.

Each maternal plant received pollen from two donors whose progeny could be distinguished by electrophoresis. Fifteen crosses were performed; we analyzed seeds from the only five crosses that showed a difference in pollentube growth rate, and the first five crosses that did not. Two of the recipient genets were rep- resented by pairs of ramets, each in a separate pot (34a and 34b, 36a and 36b; Table 2).

To quantify relative pollen-tube growth rates, pollen from each donor was applied to adjacent stigmas on each of ten to 15 pistils, as in the experiment above. Measures of percent pollen germination could not be obtained due to time constraints, but differences in percent germination are uncommon (see below). Instead, we relied on differences in pollen-tube growth rate as an indicator of relative fertilization success. Preserved styles were blind-coded to avoid unintentional bias.

Another five to ten flowers on each plant received mixtures of pollen from the two donors and were allowed to set fruit. Pollen from each donor was used to cover two stigmas per flower, so each flower received about 1,645 \pm 192 grains $(\bar{X} \pm 1 \mathrm{SD}, N=6)$. This is enough pollen to foster strong competition for ovules because only about $\mathbf{3 0 0}$ grains are needed for full seed set (Spira et al., unpublished data).

Mature fruits were collected and progeny were scored at the GPI locus to determine whether nonrandom fertilization occurred. For each cross, we scored enough seeds to detect a $10 \%$ difference from the null hypothesis of $50 \%$ sired by each donor (100 seeds for a homozygous, unique father, and 300 seeds for a heterozygous one; $P<0.05, \chi^{2}$ test). In one cross (Recipient 33), we scored additional seeds in order to determine whether a $7 \%$ difference from the null hypothesis was significant at $P$ $<0.05$. To control for variation among fruits, we used five to ten fruits per cross and scored an equal number of seeds from each fruit. Seeds were nicked to induce germination, which averaged $70 \%-90 \%$. We assumed that ungerminated seeds did not differ in paternity, but this could not be confirmed.

Due to nonsynchronous flowering of particular GPI genotypes, only two of the maternal plants received pollen from two outcross donors. The rest received self- vs. outcross pollen. Comparing self- and outcross pollen poses a problem if self-pollen is less likely to sire viable seeds in the absence of pollen-tube competition (e.g., Schemske, 1983). In this case, nonrandom paternity could be due to weak self-incompatibility and/or abortion of selfed embryos. The following experiment was conducted to test this possibility.

Effects of self-pollen on seed set and abortion-A separate group of 18 plants was pollinated in the greenhouse in 1990, and three pollination treatments were used on each plant: outcross pollen (one donor per recipient, four stigmas covered with pollen), self-pollen (on 
four stigmas), and a mixture of self- and outcross pollen (two stigmas each). Each plant received pollen from a different outcross donor. On a given plant the treatments were alternated until we obtained at least two fruits per treatment; additional flowers were pollinated to test for effects of pollen source on fruit abortion. Seed set per fruit was scored 2 wk after pollination, when unfertilized ovules were still visible but young seeds had nearly attained their final size. The vast majority of seeds were pearly white and about $3 \mathrm{~mm}$ long at $2 \mathrm{wk}$. Seeds that were less than half the size of these normal seeds were scored as "aborted," including those that were about twice the size of unfertilized ovules. Most of the seeds in this category were deflated, brownish, and clearly nonviable. Unfertilized ovules were uniformly small ( $<1 \mathrm{~mm}$ long) and brown.

\section{RESULTS}

Timing of pollen tube growth and callose plug formation-Field experiment-After $3 \mathrm{hr}$, a mean of $53 \%$ of the grains had sent tubes to the base of the style, while $57 \%$ had tubes at the base of the style after $6 \mathrm{hr}$, and $62 \%$ after $9 \mathrm{hr}$. The only significant difference between means was for the $3 \mathrm{vs} .9 \mathrm{hr}$ treatments (Tukey tests, $P<0.05, N=25$ ). Maternal plant explained $18 \%$ of the variance in the number of tubes per style $(P<0.001$, mixed model twoway ANOVA). We saw no evidence of pollentube attrition (sensu Cruzan, 1989). In this experiment and others, the number of tubes at the base of the style closely approximated the number at the top.

Laboratory experiment-Percent pollen germination was similar for $3-\mathrm{hr}$ vs. 5 -hr incubations $(62 \%$ vs. $61 \%, N=30)$. This agrees with other experiments in which most grains germinated within $1 \mathrm{hr}$ (A. Snow, personal observation), and is consistent with germination rates on unpicked flowers (reported above).

Older pollen-tubes had callose plugs further down the style than did younger tubes. Midway down the style, the proportion of tubes with plugs was $0.16 \pm 0.02$ (SE) after $3 \mathrm{hr}$, as opposed to $0.64 \pm 0.05$ after $5 \mathrm{hr}(P<0.001$, paired $t$-test). Thus rates of callose plug formation can be used as a measure of pollentube development over time.

Comparisons of pollen from different donors-Pairs of pollen donors often differed with respect to pollen-tube growth rate (Table 1), but differences in percent germination were rare (see below). Obvious and statistically signifi- cant differences were seen in pollen-tube growth rates, even when sample sizes were relatively small $(N=6)$.

Different pairs of pollen donors were compared for each recipient. Pollen-tube growth rates were significantly different for three comparisons between outcross donors, and marginally significant for a fourth (Table 1). Selfpollen differed from outcross pollen in nine out of 16 comparisons, but self-pollen-tubes were not always slower, as reported for some other species (e.g., Weller and Ornduff, 1989). In four crosses, self-pollen-tubes grew faster than outcross tubes.

These differences between donors could be influenced by both the time needed for pollen germination and by pollen-tube growth rates. We also tested for differences between donors in percent germination after $3 \mathrm{hr}$ (germination did not increase after $3 \mathrm{hr}$ in the experiment above). Significant differences were found in only two of the 20 crosses shown in Table 1 . Both of these involved Recipient 3, for which self-pollen had lower germination than Donor $\mathrm{A}$ and Donor B $(P<0.05$ and 0.01 , respectively). In both cases, self-pollen also grew more slowly than pollen from either outcross donor $(P<0.01$ and 0.10 , respectively, Table 1$)$. In general, then, differences between donors in percent pollen germination were negligible. When they did occur, they did not confound major differences in pollen-tube growth rates.

The hierarchy of donor rankings was consistent within recipients. For example, on $\mathrm{Re}-$ cipient 1 , tubes from both self-pollen and Donor A grew more quickly than tubes from Donor $B$, and no difference was seen between selfpollen-tubes and those from Donor A. Likewise, on Recipient 2, both self-tubes and those from Donor B were faster than those from Donor A, but they did not differ from each other. This consistency provides further evidence that the callose plug method is a reliable one for comparing pollen-tube growth rates.

Other findings also suggest that differences between donors are robust. One of the 1988 crosses using field-grown plants was repeated in the greenhouse in 1989. The results were remarkably similar. On Recipient 2 , self-pollen was faster than pollen from Donor $\mathrm{A}$ at $P<$ 0.0006 in $1988(N=8$; Table 1$)$ and $P<0.006$ in $1989(N=15$, paired $t$-test, data not shown). Also, comparisons between two other pairs of donors grown in pots outdoors gave the same results in 1989 and 1990 (Snow and Spira, unpublished data). Finally, similar results were also obtained from two ramets of Recipient 34 in the present study (Table 2). These preliminary results suggest that different years and 


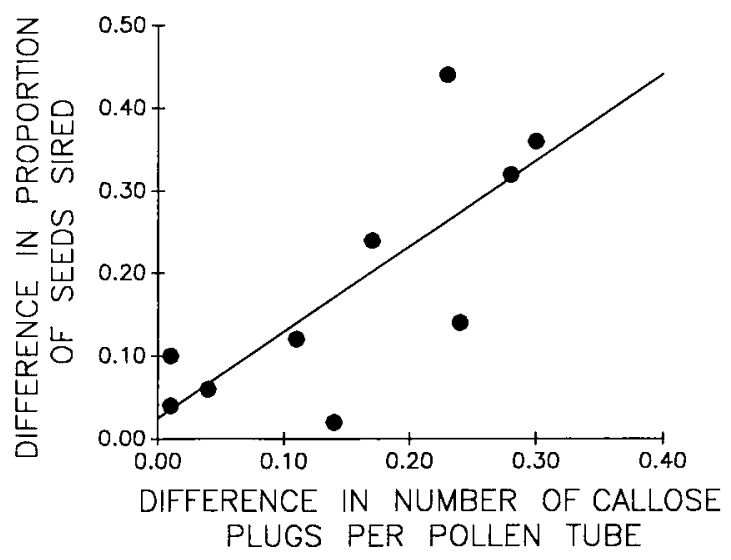

Fig. 1. Correlation between differences in pollen-tube growth rates and differences in the proportion of seeds sired by pairs of pollen donors. The latter represents the sum of the difference above and below an expectation of 0.50 for random fertilization. Same data as in Table $2\left(r^{2}\right.$ $=0.60, F=11.84, P<0.01, N=10$; regression line shown).

environments did not alter the relative success of two donors on a given recipient.

Pollen-tube growth rate and nonrandom fertilization - Pollen-tube growth rate was a good indicator of a pollen donor's ability to sire seed under competitive conditions. In all of the recipient plants, a significant difference in pollentube growth rates was associated with nonrandom paternity in the expected fashion (Table 2; Fig. 1). In no case did a donor with fast pollen-tubes sire fewer seeds than its competitor, nor did a donor with slow pollen-tubes sire more seeds. In four crosses, the donor with faster pollen-tubes sired $62 \%-72 \%$ of all seeds. In one cross, however, a strong difference in pollen-tube growth rates was associated with a relatively weak difference in the number of seeds sired ( $57 \%$ by the faster donor). Therefore, the correlation between these two variables is not a tight one $\left(r^{2}=0.60, P<0.01\right.$; Fig. 1). Some of the variation in siring ability of donors might be due to differences in percent pollen germination, which was not quantified in this experiment. This is unlikely, however, because a previous experiment showed that donors rarely differed in percent germination after $3 \mathrm{hr}$ (see above).

Self-pollen grew more slowly than outcross pollen in four out of eight crosses, but in the previous experiment self-pollen was sometimes faster than outcross. The ranking of selfvs. outcross pollen seems to depend on the particular outcross donor involved, as shown in Recipients 1-4 (Table 1) and the two ramets of Recipient 36 (36a, 36b; Table 2).

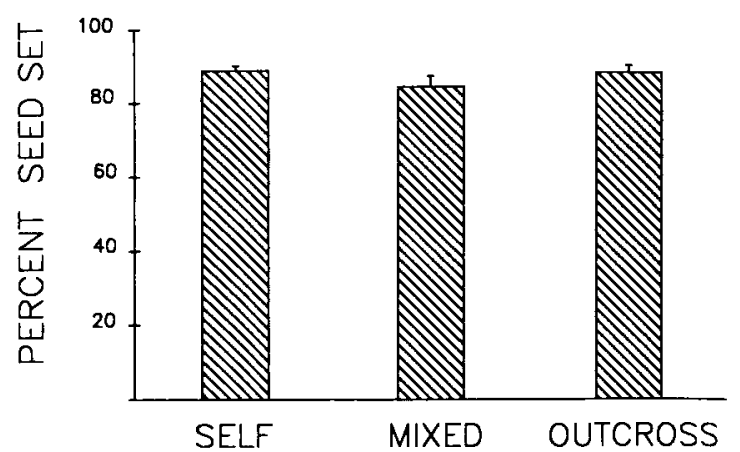

Fig. 2. Percent seed set following self-, mixed, and outcross pollination. Mean $\pm 1 \mathrm{SE} ; N=14$ (each observation is the average from two fruits per plant). The mean percent of embryos that aborted was very low: 0.6 (self), 0.7 (mixed), and 1.3 (outcross).

Seed set and abortion from self-and outcross pollen-Pollen source had no effect on fruit or seed production. Every pollinated flower initiated a fruit, and the proportions of fruits that aborted were $0.13,0.16$, and 0.17 for self-, mixed, and outcross pollinations, respectively $(N=80,73$, and 76 initiated fruits; data pooled from all plants). Thus, self-pollinations produced slightly more fruits, but differences between treatments were not significant ( $G$ tests).

Seed set per fruit was uniformly high across treatments, and very few embryos aborted (Fig. 2 ). The mean number of ovules was $126 \pm 4$ (1 SE, $N=42$; pooled data from all treatments). On average, $87 \%$ of the ovules produced viable seeds, and only one percent of the seeds apparently aborted ( $N=42$ fruits). Even with saturating pollen loads, then, a portion of the ovules appeared to remain unfertilized. This phenomenon has been reported in many other species as well (see Snow, 1986).

\section{DISCUSSION}

The rate of callose plug development was a sensitive indicator of pollen-tube growth rate. By comparing pairs of pollen donors in the same stylar environment, significant differences could be detected with relatively small sample sizes $(N<10)$. Aizen, Searcy, and Mulcahy (1990) used a similar approach to demonstrate slower growth of self-pollen as compared to outcross pollen in Dianthus chinensis. They noted that much of the variation in pollen-tube growth rates was due to among-flower variation, and that within-flower comparisons may be needed to detect cryptic self-incompatibility. Such comparisons are possible in many species with lobed or branched stigmas (e.g., Cruzan, 1990). Within-flower compari- 
sons are also more meaningful biologically, since pollen competition occurs at the level of single flowers. A further reason for using this approach is that pollen-tube growth rates can be influenced by interactions between donors (Sari-Gorla, Ottaviano, and Faini, 1975; Cruzan, 1990). Ideally, one should examine mixed pollen loads on the same stigma, but this makes it extremely difficult to identify pollen-tubes from different donors.

Individuals of $H$. moscheutos from a natural population often differed with respect to pollen-tube growth rates. These differences were repeatable in different seasons and growing conditions (field, field garden, greenhouse). Because differences in pollen competitive ability are maintained in a variety of environments, we infer that this trait is not controlled solely by microsite conditions in the field. Subsequent studies showed that differences between outcross donors were maintained across maternal genotypes (Snow and Spira, in press). Likewise, we found consistent differences between self- and a variety of outcross donors, but the competitive ability of self-pollen varied among individuals (Snow and Spira, unpublished data). Further experiments to determine genetic and environmental influences on pollen-tube growth rates are in progress.

The genetic consequences of differential pollen-tube growth rates depend on whether faster growing pollen sires a disproportionate number of seeds under competitive conditions. Here we show that relative pollen-tube growth rate was a good predictor of whether seed paternity within fruits was nonrandom. This is not surprising, given that seed abortion is uncommon and selfing does not depress seed set (Spira, 1989; this study).

The magnitude of differences in seed paternity is comparable to previous demonstrations of nonrandom paternity in other wild species (Marshall and Ellstrand, 1986; Snow and Mazer, 1988; Bertin, 1990), and is clearly associated with differential pollen-tube growth rates. For the ten crosses in Table 2, the magnitude of the difference in pollen-tube growth rates was roughly correlated with differences in seed set $\left(r^{2}=0.60, P<0.01\right.$, Fig. 1). We did not expect to find such a close correlation because our measure of differences in pollen-tube growth rates is a relative one, and the recipient plant influences average growth rates irrespective of donor.

We conclude that pollen-tube growth rates can be used in lieu of electrophoretic markers to estimate the frequency of nonrandom fertilization in populations of $H$. moscheutos. This approach allows comparisons between indi- viduals lacking unique electrophoretic markers (a common problem) and is far less time-consuming than electrophoresis. Ultimately, however, both approaches should be used in concert to understand the magnitude of unequal fertilization rates.

\section{LITERATURE CITED}

Aizen, M. A., K. B. Searcy, ANd D. L. Mulcahy. 1990. Among- and within-flower comparisons of pollen-tube growth following self- and cross-pollinations in $\mathrm{Di}$ anthus chinensis (Cryophyllaceae). American Journal of Botany 77: 671-676.

Barnes, D. K., And R. W. Cleveland. 1963. Genetic evidence for nonrandom fertilization in alfalfa as influenced by differential pollen-tube growth. Crop Science 3: 295-297.

Bateman, A. J. 1956. Cryptic self-incompatibility in the wallflower: Cheiranthus cheiri L. Heredity 10: 257261.

Bertin, R. I. 1982. Paternity and fruit production in trumpet creeper (Campsis radicans). American Naturalist 119: 694-709.

- 1990. Patterns of nonrandom paternity in Campsis radicans. American Midland Naturalist 124: 153163.

Brewbaker, J. L., AND S. K. Majumder. 1961. Cultural studies of the pollen population effect and the selfincompatibility inhibition. American Journal of Botany 48: 457-464.

Brown, M. L., AND R. G. Brown. 1984. Herbaceous plants of Maryland. Port City Press, Baltimore.

Casper, B. B., L. S. Sayigh, and S. S. Lee. 1988. Demonstration of cryptic self-incompatibility in distylous Amsinckia douglasiana. Evolution 42: 248-253.

ClegG, M. T., and B. K. Epperson. 1985. Recent developments in population genetics. Advances in $G e$ netics 23: 235-269.

Cresti, M., and J. L. van Went. 1976. Callose deposition and plug formation in Petunia pollen-tubes in situ. Planta 133: 35-40.

Cruzan, M. 1989. Pollen-tube attrition in Erythronium grandiflorum. American Journal of Botany 74: 471476.

- 1990. Pollen-pollen and pollen-style interactions during pollen-tube growth in Erythronium grandiflorum (Liliaceae). American Journal of Botany 77: 116122.

Dumas, C., AND R. B. KNox. 1983. Callose and determination of pistil viability and incompatibility. The oretical and Applied Genetics 67: 1-10.

Gottlieb, L. D. 1981. Gene number in species of Asteraceae that have different chromosome numbers. Proceedings of the National Academy of Sciences of the United States of America 78: 3726-3729.

JONES, D. F. 1922. Selective fertilization and the rate of pollen tube growth. Biological Bulletin 43: 167-174.

Marshall, D. L., AND N. C. Ellstrand. 1986. Sexual selection in Raphanus sativus: experimental data on nonrandom fertilization, maternal choice, and consequences of multiple paternity. American Naturalist 127: $446-461$.

Martin, F. M. 1959. Staining and observing pollentubes by means of fluorescence. Stain Technology 34: 436-437.

MAZER, S. J. 1987. Parental effects on seed development 
and seed yield in Raphanus raphanistrum: implications for natural and sexual selection. Evolution 41 : 355-371.

Mulcahy, D. L., and G. Bergamini Mulcahy. 1987. The effects of pollen competition. American Scientist 75: 44-50.

Rust, R. W. 1980. The biology of Ptilothrix bombiformis (Hymenoptera: Anthophoridae). Journal of the Kansas Entomological Society 53: 427-436.

Sari-Gorla, M., E. Ottaviano, and D. Faini. 1975. Genetic variability of gametophytic growth rate in maize. Theoretical and Applied Genetics 57: 37-41.

SAS InSTITUTE, INC. 1985. SAS user's guide: statistics. SAS Institute, Cary, NC.

SCHEMSKE, D. W. 1983. Breeding system and habitat effects on fitness components of three neotropical $\mathrm{Cos}$ tus (Zingiberaceae). Evolution 37: 523-539.

, AND C. FENSTER. 1983. Pollen grain interactions in a neotropical Costus: effects of clump size and competitors. In D. L. Mulcahy and E. Ottaviano [eds.], Pollen: biology and implications for plant breeding, 404-410. Elsevier, New York.

SCHOEN, D. J. 1983. Relative fitness of selfed and outcrossed progeny of Gilia achilleafolia (Polemoniaceae). Evolution 37: 292-301.

SNow, A. A. 1986. Pollination dynamics in Epilobium canum (Onagraceae): consequences for gametophytic selection. American Journal of Botany 73: 139-151.

- 1990. Effects of pollen load size and number of donors on sporophyte fitness in wild radish (Raphanus raphanistrum). American Naturalist 136: 742-758. -, AND S. J. MAZER. 1988. Gametophytic selection in Raphanus raphanistrum: a test for heritable variation in pollen competitive ability. Evolution 42 : $1065-$ 1075.

, AND T. P. SPIRA. In press. Pollen vigor and the potential for sexual selection in plants. Nature.

Soltis, D. E., C. H. Haufler, D. C. Darrow, and G. J. GASTONY. 1983. Starch gel electrophoresis of ferns: a compilation of grinding buffers, gel and electrode buffers, and staining schedules. American Fern Journal 73: 9-27.

SPIRA, T. 1989. Reproductive biology of Hibiscus moscheutos (Malvaceae). In J. H. Bock and Y. B. Linhart [eds.], The evolutionary ecology of plants, 247-256. Westview Press, Boulder, CO.

Waser, N. M., M. V. Price, A. M. Montalvo, and R. N. GrAY. 1987. Female mate choice in a perennial wildflower, Delphinium nelsonii. Evolutionary Trends in Plants 1: 29-33.

Weller, S. G., ANd R. OrndufF, 1977. Cryptic selfincompatibility in Amsinckia grandiflora. Evolution 31: 47-51.

- AND - 1989. Incompatibility in Amsinckia grandiflora (Boraginaceae): distribution of callose plugs and pollen-tubes following inter- and intramorph crosses. American Journal of Botany 76: 277-282. 